\title{
Challenges of Imprisonment in Afghanistan, the Necessity for Tendency to Alternatives
}

\author{
Jafar Kousha* \\ Faculty Member, Department of Law, University of Shahid Beheshti, Tehran, Iran \\ Email: jkoosha@yahoo.com
}

Eid Mohammad Ahmadi

PhD Student of Criminal Law and Criminology, Department of Law, University of Shahid Beheshti, Tehran, Iran

Email: eym.ahmadi14@yahoo.com

\section{Doi:10.5901/mjss.2015.v6n6s6p148}

\begin{abstract}
This article discussed and explored causes some of the inefficiencies and challenges of prison, jail punishment and its ineffectiveness in preventing recommitting the offenses in Afghanistan. In the section of reasons, the old and the central power of the court, the maximum approach of lawmakers to jail and court predominant use of this punishment has been identified. Health, economic, familial, and social problems, and finally, the problem of population density and a pessimistic view of society to criminal justice system is a consequence of this approach. Finally, the study proposed that policymakers and regulators trying to reform the criminal court, penal policy approach and the use of other sentences (probation, suspension of punishment and alternatives to imprisonment) instead maximum of imprisonment.
\end{abstract}

Keywords: criminal justice system, reform of court, jail, criminal policy adjustment and alternatives to imprisonment.

\section{Introduction}

Considering the wide range of issues of crime, punishment and deterrence, form of punishment and the complexity of social conditions and its direct impact on legislators' attitudes have created broad and deep changes in the type of punishment. Prison as the most important and most widely used preventive punishments and challenges faced much criticism; so now the criminal justice system must take special measures to achieve crime reduction, social security and preservation goals of punishment, and it should adopt the necessary measures on prison alternatives.

Afghanistan is dealing with the challenges and problems about the prison and jail more than many other countries. Reasons and backgrounds of these deficiencies is so clear that Afghanistan is now the legacy of the old, inefficient and unprofessional justice system that the old structure of both software and hardware causes more complexities in setting policy and applying punishments; so as it makes difficult or impossible to achieve the objectives of the efficient penal system.

For this reason "Ben" agreement in December 2001 is the beginning of a new chapter in Afghanistan's transition and rotation; one of the issues that is concerned and emphasized is the reform of the justice system and its administration.

In the current legislative Afghanistan criminal justice system, prison has its own first place. Subsequently, the dominant thinking and practice in the courts considers this punishment as the most appropriate penalties to punish and reform criminals. In addition to the legislative and judicial approaches, we should also add hardware inefficiencies, such as lack of adequate buildings for keeping convicts and as well as software challenges such as lack of sufficient judges and deficiency of the less educated judges; with these components prison punishment system is faced with questions.

Does jail punishment is efficient? What are the important challenges of prison in Afghanistan? What are the strategies for releasing from them? It is clear that creating a society that relies on democracy, legitimacy and security in Afghanistan requires an effective system for criminal and justice policy.

Reform of the justice system and criminal policy is a matter of human rights in Afghanistan. Justice that only through the existence of a strong judicial system is possible is the most important tool for sustainable peace.

Therefore, the necessity for studying the shortcomings of the criminal justice system of Afghanistan is obvious. This research aims to demonstrate problems of prison sentences and provide solutions to get rid of them, according to 
new data and results of criminal and penal sciences.

It is worth mentioning in this study flaws and lack of regular updating structurally criminal policy, legislative and the judiciary as a whole will be discussed, and such details and examples of challenges requiring another opportunity.

The first speech, the shortcomings of the prosecution, the origin of the increase in prison population

When it comes to penalties, especially among ordinary people, most of them in prison come to mind, for a variety of punishments, prisons become more common and the public, prison angel criminal sanctions. That general principle and necessity of detention against dangerous criminals, it is inevitable. However, the maximum use of this type of enforcement, despite the presence of the international community in the country and global programs to reform the criminal justice system as well as the efficiency with serious questions face prison sentences that one of the reasons is the old structure and competencies too Authorities, prosecutors and judges prosecutors that we discussed here.

A) Updating the Absence of the Prosecutor (Saranvali)

This is the primary link between the police and the courts. Structurally independent of the executive branch in its implementation. The main tasks of the Office of the Prosecutor (Saranvali), investigation of criminal cases, and prosecute criminal proceedings against the accused in courts.

\section{History of Establishing the Court}

In custom law, the court is a French organization, and as it is established in France, the other countries follow it in establishing the court. The root of this organization refers to the thought and method of other kings in France. Since the centuries ago, the rulers of France have the representatives in the courts to defend their interests. The representatives had the important role in prosecuting the offenders and punishing them, in addition, they pay daily to Treasury. In addition to financial profit, it has the government aspect, and conducting the punishment is the sign of power of the king and it shows them as the powerful ruler. In the case of laxity in punishment of the offenders destroyed glory and power of the kings. Until the fourteenth century the practice was that the representatives of the King could receive the fines and accepted the representation in other cases and they were involved the proceedings. As early as the fourteenth century, the representatives of the king were prohibited to accept other representations and they must only defend the rights of the king. Their job was hereditary and passed on to the heirs and were known to the public claims.

After the advent of Islam in the territory of the justice system, we can see the court.

To the Sultans of Egypt institution called "Daraldl" established in Cairo on certain days, king and chief justice among the people to justice and public lawsuits and complaints dealt with. But before the king and the chief justice to ensure justice court session will be held; the noblest virtue and piety secretary was appointed as public prosecutor to the people's demands to the King and the Chief Justice to provide completely unbiased. Today, nature of the work, like the duty of the public prosecutor is investigating judges.

Prosecutors should enjoy the three characteristics: the world of impartiality and representation of the people to reflect their demands.

The history of court in the country dates back to 1901. The fundamental organization of a system of preparation published. Accordingly, in the center, the State Council and the provincial government was established by Chief and consultation meetings .Trial offending officers were assigned to the State Council consultation meetings. The charges follow an officer was convicted in various stages of trials require lawyers to pursue litigation against the officers charged and do their duty.

At a later stage, in accordance with the needs of the times, the need was felt to God and to establish a state on the territory of its legal position, the text as an appendix to the Constitution of Afghanistan basic, was added to the organization. From this point, for the first time, the lawyer found guilty, the prosecutor was officially legislated.

The constitution in 1964, the Department of "prosecutor" established its place in the constitution and in Article 103 stipulates:

"Investigation by the public prosecutor as part of the executive branch of government is conducted in accordance with the provisions of this law".

In the fourth step, the agency has more strength and a separate law, "the law of Saranvali" dated 26 November 1343 , Article 24 was drafted and enforced.

In this law, the prosecutor's office as supreme public prosecutor and the Attorney Saranval (Chief Prosecutor) as its president, is introduced.

Two years later, on 15 March 1966 Saranvali applicable law and regulatory law was repealed in 1964 Saranvali. 
The only change that has occurred in recent legislation, the President of the General Prosecutor's Office to the Minister of Justice, was buried.

Thus, the history of this institution for nearly a century in his name. But with all the ups and downs that have taken on different occasions, has suffered from shortcomings and disadvantages. Responsible for detecting crime and punishment is not only the court, but in addition to efficiency and effectiveness in the rehabilitation of offenders and reduce crime statistics also show along with the security and defense of public rights, the rights of defendants and the convicts are its unique. In Afghanistan, structure and powers of this body would sometimes cause an increase in crime and the consequences of the conviction as well.

\section{Jail Oriented Structure and Competent Court}

"Organization whose task is to protect the rights of the public prosecutor, supervising the implementation of laws and prosecution of criminals is".

In explaining the status of prosecutors in all countries can be said that the public prosecutor is a judicial body without any due process rights, and its main task is to prepare the indictment the public and facilitate Court. Despite the legal nature of the judicial body, but in Afghanistan, the organization is part of the executive branch that this type of structure, the approach is more of imprisonment.

\subsection{Authoritarian structure of prosecutors}

History in this context court (the executive) during the autocratic monarchy and returns. French rulers for centuries had a representative on his behalf in court to defend the interests of the king. The representatives of the prosecution and punishment of offenders had an important role and its daily revenue was credited to the royal treasury. In addition to financial benefits, the aspects of governance and strict enforcement of penalties, a sign of the power of their rulers and powerful ruler.

During the French Revolution, while accepting the need for the institution of criminal prosecution, rather than the complete elimination, of limited authority. Today, in most countries the court is judiciary, but Afghanistan is under the executive branch. This structure is disproportionate to the nature of the duties of prosecutors and would overcome administrative nature and disposition of cases and the extreme power source is to avoid the institution of legal actions. Subsequently, it causes unbalanced behavior and intense practice with the defendants and convicts. The dominant approach puts the power and the prosecution and trial process, the audit system. The output of this procedure is the increase in the prison population and its consequences.

\subsection{Competence of Court Sentence}

The court is the highest-ranking prosecutor that many of the duties of prosecutors under him and after the determination is made, the official confirmed. The position of the Attorney General (AGO Saranvaly) in Afghanistan's legal system is the discussion of the issues, it is necessary because so much work has been done about it.

Focus on judicial duties. The first task of the judicial prosecutor (Attorney Saranvaly) is presiding over the court. The prosecutor is the head of the prosecution service and the court everything is done under the supervision of the prosecutor.

The most important functions of the court, to prosecute crimes, criminal proceedings and criminal court.

Protest vote in criminal courts the powers and duties of the other court.

The tasks and critical in terms of the Criminal Procedure Code following the take.

B) Organizational structure of prosecutors

It is very big and wide, hierarchical organization is run.

The department is composed of the Attorney General, the Supreme Court (Supreme Court), Courts of Appeal and Primary Courts. In addition to the civilian prosecutor's offices, military special court that only the crimes committed by the armed forces, police, national security and other administration officials that a military organization, the handle.

All these sectors headed by the Attorney General (AGO Saranvaly) is run.

The Attorney General has four vice presidency is sixteen. Of chief prosecutors, deputies and heads of various departments, the Supreme Council held that the raison d'etre of the Council, better performance and accurate monitoring 
duties of institution are mentioned. ${ }^{8}$

\section{The Extent of the Competence of the Prosecutors, Source of Increasing the Prisoners}

Before the competencies and critical expression, it is necessary that the scope and range of appeal and appeal in the Code of Criminal Procedure and the law and jurisdiction of the Saranvaly Afghanistan. Today, appeal has been accepted as a basic human right in the judicial system. In this regard, the Criminal Procedure Act, a license appeal based categories crime rate and courts are divided. Revised diagnostic criteria vote, the penalty specified in the court order is not a punishment foreseen in law for the defendant acted contrary to the Code of Criminal Procedure of the revised criteria for diagnosing vote, the penalties provided for in law for the acts charged.

1. The primary objection to the court on charges of obscenity:

If the public prosecutor wants to appeal the verdict primary court that "the decision to acquit the accused is issued". Thus, any conviction and punishment of crimes against the public prosecutor cannot appeal and is considered definitive. But against any ruling acquitting the accused, the appeal is allowed. Therefore, any acquittal, the criminal law in Afghanistan cannot be definitive. In other words, if the primary court to charges of offense, the accused are convicted; this decision and the decision is final and irrevocable. If the court to give verdict acquitting the accused, the case is on appeal by the public prosecutor.

Thus, it seems appeal of the acquittal of the offense charged, firstly from power-oriented approach and the power is in the court. While prosecutors should be charged only on proving his duty to defend the rights of the accused as well; this means that if there is no reason and evidence to prove guilt, prosecutors have the benefit of the accused to defend him. Second, ideas and ways appeal and the appeal should be to the reasons stated in the law. Since the acquittal in accordance with the principle, the objection, it is in need of a strong legal reasons and directions. While the protest permits acquittal if not to provide legal ways and Paragraph 4 of Article 246 of the criminal law enforcement, witness the claim. Order that the legal aspects of this paragraph as opposed to independently judge the law, and so protests will be considered. The possibility that the verdict on punishment if the public prosecutor or the presumption of innocence, the right to protest against the law in both its form. Therefore no final decision can be opposite in crime. Obvious consequence of such legislation, incomplete, prolong the proceedings and will be increasing the number of prisoners.

2. Protest the verdict primary court on charges of misdemeanor

Misdemeanor crimes, according to law enforcement criminal jurisdiction of either the public, the prosecutor has the right of protest. In cases where a criminal act punishable by imprisonment or fine or both, but the court only sentenced to a fine. Article 480 of the Penal Code, for example, the judge in sentencing dishonest, three options are optional, but criminals sentenced only to a fine, the right to appeal to the public prosecutor is fixed.

Second, if the offender is sentenced to less than half of the maximum punishment provided for the criminal act, the public prosecutor has the right to appeal. Such as paragraph 3 of Article 464 of the Penal Code with a maximum penalty of five years in prison usurper and his court to two years in prison for less than half the maximum of the sentence. However, the law and jurisdiction of the court, the vote restricted Primary Courts of Appeal stated :If the primary court on a misdemeanor charge of up to one year in prison or a fine up to the amount of one hundred thousand Afghan sentence is punishment, [prosecutors] can appeal (appeal), welcomes you". Therefore, the primary court on crimes against on the basis of this law are final, and misdemeanor offenses to one year imprisonment penalty or a fine of one hundred thousand Afghanis, the primary court's ruling is final and the prosecutors cannot appeal.

The comparison between the criminal and administrative law and the jurisdiction of the court, there is an obvious difference regarding the license appeal. Unlike criminal court of law, whether the conviction or acquittal of all primary rules, is certain. Unlike criminal law implementing the prosecutor the right to appeal his acquittal. Misdemeanor crimes, according to the law court to determine the penalty for the offender to one year in prison, is that the average sentence, the final; while the Penal administrative law, if an act punishable by law "lien" (e.g. imprisonment average) and a court for less than half the maximum penalty (e.g. two years) is convicted, would be objectionable. Also, if the punishment of imprisonment or fines is criminal law and the criminal court to be sentenced to a fine of up to one hundred thousand Afghan law, final court sees him. If the applicable law to accept the verdict of the criminal complaint. The industry and legislative techniques in Afghanistan has been faced with challenges and continue to see conflict between the laws of different perspectives on a topic approved, and not a single reference to expert and professional, yet necessary legislation for the unity of law is not respected. But since that law enforcement of jurisdiction law is approved in Act of 5.5.2014, and the prosecutors is the final authority and criminal enforcement law according the enacted law on 7.10.2014, 
and the cases of against the law is abolished; as in the past the last line of Article 282 of the Act, we read: "and other provisions are revoked that are contrary to the provisions of this Act."

So, now that the law is valid in the Penal administrative law appeal, and it became clear that the approach of the public prosecutor's competencies to revise the law to approach the maximum and expansion and even crimes against the majority of cases, it does not provide such a re-examination of the case, the rulings of the court to acquit the accused appeal is considered. Look for the costs of the social, economic, family and so on society that seems unnecessary and necessary. Aside from all these criticisms, as passed, another major drawback is that the criminal administrative law Paragraph 4 of Article 246 states:

"Apart from the cases mentioned in entries 2 and 3 of this Article, the defendant or prosecutors cannot seek to appeal the ruling, unless the judgment appealed against the law or error in the application or interpretation of the findings made in the judgment of nullity or invalidity is located in the administrative impact of the ruling is that." What is the purpose of these exceptions? Unless all the license of any court appeal of rulings that have been issued, shall be documented for legal reasons? No doubt protest the court order should be based on legal grounds and legal documentation for the items that are listed in Paragraph 4 of Article 246, and that it will appeal to independent, could be indicative of two things, first is that the appeal based on the spine 2 and 3 of this Article may be taken without due and legal aspects that are not accepted at all. Second, no judgment cannot be the author of uncertainty and in accordance with paragraph 4 of this paragraph if they meet any legal grounds to appeal. This trend will lead to weakness and unreliability of the judicial system that is not acceptable.

\section{Protest Against Court of Appeal Rulings}

According to the court, "If the Court of Appeals of misdemeanor offenses to two years imprisonment or a fine of two hundred thousand Afghanis or both to the amount of the criminal penalty, the prosecutor can appeal". Executive in criminal law, criminal misdemeanor and felony bail of two years' imprisonment or a fine up to two hundred thousand, and in any case the prosecutor on the verdicts of Courts of Appeal in the case of reasons, has the right to appeal. Thus, in this section there is also friction between the authority and the primacy of law in case of criminal enforcement, presupposes that no definitive judgment can be appealed and the consequences of such a policy is issued, the fate of the convicted and increased the prison population will stay respectively.

\section{The Authority of the Attorney General in the Crimes}

Afghanistan's court system, prosecutors opened a criminal case in the various institutions, adrift in circulation and it is difficult to imagine an end to him.

The law says:

1) "When the prosecutor appealed the verdict and the decision of the Primary Court of Appeal in crimes or other content, to comply with the provisions of this law in order to decide the case next to the prosecutor of the Supreme Court sends.

2) If the Attorney General or Deputy Attorney's Office prosecuted the decision of the Supreme Court is satisfied that the crime does not agree with the verdict, appeal to the Board of sends his reasons. "

Of the hierarchy, highest court, Chief Prosecutor and then, as the Court of the Supreme Court. In proceedings in a criminal case, the court jurisdiction of the Supreme Court, protesting the court ruling and will appeal .This means that, to deal with a charge of Primary Court is the court of appeal and the third to the Supreme Court (Supreme Court). The public prosecutor of the Supreme Court if the court was satisfied with the court's ruling, the verdict is not final. For the fourth time, Chief Prosecutor in accordance with paragraph 2 of Article 24 Qualification protest the Supreme Court's verdict. The competencies required for successive prolong Darcy process and increase the waiting period for final disposition he is sentenced. It is also possible to increase the long-term deprivation of liberty and aggravated sentence of imprisonment to life imprisonment lead. Following the establishment of the court with such wide competencies, an expansionary policy towards it. In this approach, almost severe culpability of the accused and contrary to the principles of criminal law, the defendant must prove its lack of culpability or lack of intensity. Central power and ignoring the rights of the accused in this policy is evident. But the court must defend the right of the accused as it defends the society, and if the accused not proven guilty in a court or not set severe penalties on the offender by the judge, it should not insist on proof of the crime and the severity of it. 


\section{The Second Speech, Certain Challenges of Prisons}

Today the majority and dominant in Afghan courts determine sentences on offenders. This approach is facing a lot of problems, while prisons and detention centers from different directions. Here are some important issues to be addressed.

\subsection{The Hardware Challenges of Prisons}

Suitable for freedom in the provision of health facilities, the health of prisoners, rehabilitation and closely monitoring them is very important. At the beginning of a new trend in the country (from 1382), or in some provinces, there was no building prisons for prisoners or very poor. The very old buildings, old and no sanitary facilities, health and recreational. Today there are prisons in all 34 provinces and in most prisons are built. In some provinces, the public office buildings or rented houses are used.

During more than a decade, although the construction of places of deprivation of liberty is a good achievement, but the trend is not considered a growing prison population, so many buildings built in the period of several years with the bulk of the prison population exceeds its capacity. Plant and equipment due to the heavy use already problematic and some of them are disabled. Overcrowding in prisons and detention centers and some capacity is a serious problem and major. So that in most provinces, averaging half a meter per prisoner is assigned here. Overpopulation in prisons can be converted into punishment of imprisonment doubled and the challenges increase. Addiction, chronic and infectious diseases, immoral behavior, learning style of the consequences of committing a crime and is punishable by imprisonment and a lack of appropriate facilities in prison.

The problem of lack or deficiency of detention is not less than the problems of prisons. According to the law, there should be at least one building for detention in the center of every governorate. In Afghanistan, there are 364 governorates and nearly half of the governorates do not have jails. Women's Prisons has not been made in any of the governorates. The suspects and the accused for a short time at the public security police to seize the homes of the district retained and then transmitted provinces. The problem transfers to the provinces, away from family, crime, lack of access to evidence that the deficiencies in women's doubles. As a result of a long process of trial prosecutors at various stages of the proceedings is the maximum authority, brings unbearable problems; because these factors cause the person charged or convicted and spent time in a state of ambiguity and uncertainty of the situation irreparable consequences for both the individual and society.

\subsection{Software Challenges of Prisons}

Worse than any problem in prisons, the harm inflicted on prisoners. One consequence of the plurality of dense population and people living in different corners of the prison, addiction to various drugs. According to reports from within Charkhi Prison in Kabul, opium, glass, heroin, crystal and cannabis are widely used by prisoners. The number of drug addicts in prison from 2011 until the end of 2013 that have reached more than 750 people. The number of people who use drugs, into the prison, the surprising and disturbing is added. The number of addicts referred to the name of parliament and addiction severity of this category to the extent that they can be very difficult for the sun to come rooms to the prison yard. Entry of drugs into prisons in different ways possible. Because of the high cost of drugs in prison management, as well as a source of income, therefore, there is high motivation for turning to this work. Groups of the society that their activity and the transfer of materials within the prisons are traders.

As well as HIV, hepatitis and other diseases appears among prisoners. Prison environment due to population density, lack of privacy, the scope and duties, over time, cause a lack of commitment and lack of prison and chaos surrounding him that in the absence of monitoring personal health and the environment, the population density and the proximity of prisoners to other causes and transmission of viral diseases and vermin and vector replication, thus endangering the health of others. Incurable diseases such as AIDS and hepatitis through, risky sexual behaviors and drug injection and tattooing equipment transmitted, health officials must pay attention and control prisons that if timely identification and control are not planning, a serious physical harm threatens other prisoners. Unfortunately, early detection and control planning in most prisons do not exist, the community is not safe from dangers. It may be a person for a minor theft, sentenced to prison and to also develop chronic diseases. 


\section{The Third Speech Imprisonment Oriented Legislative and Judicial Systems}

\subsection{Prison-based criminal policy}

One of the reasons behind the prison population density, is punishable by imprisonment in the Afghan criminal law, punishment for most crimes had been anticipated. State Prison has placed prisoners 7 to 8 times more than the actual capacity. ${ }^{47}$ It seems that in this country, the prison population was used more as a tool for management to achieve the goal of reforming the offender and his rehabilitation, because imprisonment should only be for those who are a serious crime, and the perpetrator of the of society, to the benefit of society and their presence in the community is dangerous. Prison-based and emphasis on imprisonment in criminal law in Afghanistan so far is a mere trifle actions such as changing the shape traffic signs, ${ }^{48}$ crazy in the public, ${ }^{49}$ throwing garbage into the sea and river water, ${ }^{50}$ contaminated steam pipe, ${ }^{51}$ and in general a lot of imprisonment legislated in Article 496 of the criminal law, while some of this behavior collective conscience does not hurt the society in any way, prison is considered.

It seems that every organization and institution offers imprisonment for offenses that are not known as crimes to promote and protect their interests, and the Council of Ministers and the Parliament have approved it. It should be noted that the overemphasis of the legislators on prison (prison-based) breaks the authority of the law in society, it removes obscenity of offense and it prevents the law to do its mission for crime reduction and the fight against criminals. Perhaps today, the most important factor is the remove of obscenity of prison, and the prison-based of the Code of Criminal Procedure. Therefore, the refinement of laws aimed at relieving prison and decriminalization of minor offenses and style, greatly reduce the jail population will lead to prison inmates and the community will help to reduce the damage.

Another fundamental problem is the country's criminal policy that the vast majority of crime is regarded as a public crime of any compromise between the two sides is closed.Afghanistan in tact criminal proceedings only in the family, Article 63 and Article 359 and 517 of the Penal Code of Criminal Procedure applicable law, crimes against high-ranking officials in Article 61 of the above law and the victim being foreign diplomats in Afghanistan in Article 61, paragraph 3 Article 171 of the Crimes Act that have been deemed negligible ;as well as paragraph 4 of Article 9 of the Juvenile, Article 39 of the Law on Elimination of Violence against Women, capture customer bought the property before paying the price of private crimes are negligible. Basic aspects of the crime or the right of Allah that criminal prosecution and stimulate action within the competence of the court. Such public policy-oriented, in addition to causing corruption and corruption within the institution prone prosecutors, increase the prison population and sentenced. Some of the crimes committed and suffered as a result of a compromise between the pursuit of justice is simply out of the circle, but this policy, prudence does not allow compromise and hunky-dory, therefore, one of the necessary reforms in penal policy is the reform of the general approach of offenses, with much of the burden of adjustment policies on the backs of the courts and the prosecution of criminal cases, and if by mutual consent, criminal riot ended, these advantages will be committed several times to impose punishment.

\subsection{Detention-oriented of the judges}

Trust and judges to sentence, including the reasons that can cause an increase in the prison population. As well as the frequency of resort to temporary detention orders and agreements that led to the imprisonment of the accused jail population density. It may be said that the prison laws, judges strained and forced them to pick up the orders and predict the law, punishable by imprisonment to consider, and if authority on the use of other punishments instead of prison, they will certainly, while evidence suggests that judges, confidence and less inclined to use strategies such as commutation of sentence, parole, conversion and suspension penalties and prison sentences are also applied to alternative punishments, and in some cases, such as the issuance of a temporary detention optional and some laws that require two or more penalty and the judge is empowered to choose one of them, they prefer the use of prison and they don't consider the consequences. But in many cases the law, punishment is discretionary, the punishment is not the kind of imprisonment, but it needs to culture, training of judges and to build trust and believe in them to alternative penalties and the use of institutions such as the suspension of punishment, parole, pardon or commutation of the sentence that has been less attention. Referring to courts and judges to achieve this, the extent of probation, suspension of punishment and alternative courts have been used, the effort leads to less result, and this indicates that public opinion and the courts know prison as the best punishment regardless of the consequences of imprisonment. 


\section{The Fourth Speech-The Alternatives of Punishment, the Solution for Getting Rid of Its Challenges}

Unfortunately, today, a great part of people believe that the prison is necessary for the offenders, and the court that is influenced by these factors try to imprison the offenders, but it should be considered that first, all of the offenders are not dangerous. Second, those who are imprisoned for the first time, they don't recommit the crime, and if they do, their crimes are not so great and important. Third, there are other prison punishments and sanctions which are more effective and cheaper and equally or more offenders serving time in jail instead of allowing the teachings of the dangerous criminal, victim compensation and inked responsible for illegal acts.

Today, the prison has accepted the failure in achieving the goals. It does not cause the regret of the offender, but also, it turns to the school of recommitting the crime.

The way for getting rid of the inadequacy of prison, go into politics and policy alternatives and promote the use of security measures. The replacement policy, legislative and judicial replacement. The legislative replacement, using the teachings and penological data, especially in the case of imprisonment, solutions as an alternative to imprisonment, given the severity and importance of criteria such as crime and the personal characteristics and personality of the offender at all stages of criminal offenses forecasts. For example, a sentence to a fine of up to 329 daily and community services referred to in Article 325 of the criminal law enforcement, prison policy reflects removing. This step-by-step proper, necessary and positive move towards restorative justice and corrective rather than punitive justice, but insufficient and very limited contract. Specific proposal is to use the experiences of other countries, especially Islamic countries, which have much in common cultural symmetry, this policy development should include all simple and casual classes and categories of offenders.

The purpose of justice is the court at sentencing alternatives taking into account the type, the amount of dangerous and non-dangerous crime, social conditions and serious crime and criminal record, had predicted alternatives instead of prison sentences. As well as strengthen the competence and culture of conditional release, suspension of punishment and prison security measures in reducing injuries can have a decisive role. Nowadays, these policies and procedures adopted in the legislative and judiciary is necessary and inevitable. It should be noted that the success devise new alternatives to the traditional is to be done properly and with the intended mechanism. The basic objective of substitutions policy, avoiding prison, chronic diseases, impose heavy costs on society and that using these methods achieve a reduction of criminality, the socialization of the offender, sentenced to more stability and better enable families. This goal is achievable if the conditions of use of alternative measures are well respected.

To be successful and efficient replacement policy, we must abide by the following terms and structures.

1. Making culture: The effective implementation of alternative methods instead of prison infrastructure and cultural needs of the society and the institutions responsible for implementing them.

2. Having a clear law: In addition to culture, it is essential that there should be clear legal. The legislator should do his duty in this area and replacement method, the manner of choosing and the official for its implement should be identified. ${ }^{45}$

\section{Conclusion}

According to the findings of this research, it can be concluded that the findings in the section of causes of problems indicated that the structural inefficiencies of the court and the maximum approach of lawmakers and judges to the prison punishment cause health problems, transmission of infectious diseases and communicable diseases such as tuberculosis, hepatitis and AIDS, sexual, economic and family problems.

Prison is not only ineffective in preventing crime, but it causes recommitting crimes and a variety of methods and teaching techniques of criminal conviction. In addition, this role becomes more notable with the arrival of convicted or accused to prison both because the context and environment for specific crimes are provided .This result confirms the statistical findings.

These problems are effective in reducing public confidence in the judicial system, lack of space and the proliferation of criminal statistics prison population density should also be added. This may have been caused by prisonbased laws, punishment policies and practices of the judges and ignoring the other techniques.

It results the failure to enumerate these and many other failures that are not mentioned in this article, it should be believed that the prisons, particularly in Afghanistan have some features that cannot meet the purposes that the criminal philosophers have offered them (correctional, social reconstruction, individual and social punishment, intimidation and prevention of crime and recommitting the crime). Therefore, the prison should be seen as "a necessary evil", and in the use of this necessary evil, the least should be adequate. 
So according to the shortcomings of the present status, prison not only does not create legal security, it creates discontent in public, judicial insecurity, a sense of pessimism and discontent in people. Therefore, for providing legal protection, the feeling of insecurity, a sense of satisfaction among citizens, making deep structural reforms and basic penal system and prisons, the following should be placed on the agenda of executive and legislative penal system:

1. Modifying the structure and powers of the court.

2. Adjusting the legislative and judicial security and criminal policy alternatives.

3. Avoiding the prison-based.

4. Training for judges and staff of the criminal justice system, especially in education and culture, the use of alternatives to prison sentences. 